\title{
CAPACITAÇÃO DO BIBLIOTECÁRIO COMO MEDIADOR DO APRENDIZADO NO USO DE FONTES DE INFORMAÇÃO
}

\author{
Maria Matilde Kronka Dias \\ Regina Célia Baptista Belluzzo \\ Fábio Assis Pinho \\ Daniela Pires
}

\section{Resumo:}

O artigo trata da formação em serviço do bibliotecário como mediador do aprendizado no uso de fontes de informação. Apresenta uma proposta metodológica para capacitação de equipes bibliotecárias visando a orientação e implementação de atividades que possam contribuir para que as bibliotecas se tornem espaços maximizados de aprendizado, qualificando-as como mediadoras desse processo. Demonstra que as mudanças de comportamento, com base em metodologias científicas, contribuirão para o desenvolvimento do trabalho cooperativo e ações que favoreçam a qualidade e produtividade dos serviços bibliotecários.

\section{Palavras-Chave:}

Capacitação de equipes bibliotecárias; Mediação do aprendizado; Fontes de informação.

\section{LIBRARIAN TRAINING FOR LEARNING MEDIATOR AGENT IN THE USE OF THE INFORMATION SOURCES SYSTEM}

\begin{abstract}
:
The librarian capability of guiding the information sources system learning process, with emphasis on "learning on the job" and continuous improvement is presented. The training method proposal presented discusses the implementation of activities that will support the librarian's role and work in making the libraries a maximized learning environment, guiding and qualifying the librarian's role as a mediator-agent of the process. Team behavioral changes, based on scientific methodologies, their contribution for the improvement of team work, service quality and productivity, are demonstrated.
\end{abstract}

Key words:

Librarian training; Learning mediation; Information sources. 


\section{INTRODUÇÃO}

É, praticamente, impossível participar da atual sociedade, instável e em constante evolução, sem estar informado, sem conhecer os fatos que estão transformando o mundo. A informação é matéria prima para os indivíduos serem partícipes de mudanças na realidade social, organizacional e, consequentemente, em sua própria realidade. A informação terá valor na medida em que seja devidamente tratada e comunicada para um público capacitado informacionalmente, ou seja, um público que esteja preparado para usar a informação recebida para tomada de decisão e resolução de problemas. Para tanto, os bibliotecários precisam compreender que isso requer não apenas as habilidades básicas de uso de documentação impressa, factual ou eletrônica, mas principalmente de habilidades de pensamento, compreensão, análise e síntese, além de atitudes e agregação de valor à informação - a information literacy - para se obter condições de autonomia quanto à obtenção do aprendizado ao longo da vida.

Desse modo, os bibliotecários devem ter habilidades especiais em relação ao ensino/aprendizagem da localização de recursos, a formulação adequada das buscas, a decodificação da informação, a localização, a seleção e consulta de registros e de documentos em diferentes suportes e formatos. Aliado a isso, encontram-se também os valores éticos e legais relativos ao acesso e uso da informação. As destrezas no uso das tecnologias de informação e comunicação devem ser aprendidas com o apoio de programas institucionais, bem como os processos de determinação das necessidades de informação, sua análise e sua reelaboração e disseminação à comunidade com a finalidade de produção de novo conhecimento - eis o grande desafio para a capacitação em serviço dos bibliotecários enquanto mediadores desse aprendizado nas bibliotecas brasileiras.

Neste cenário, a educação assume papel preponderante para a absorção e aceitação de novos padrões nas interações humanas, carregadas de inovações das tecnologias da informação e comunicação, respeitando-se as tradições sociais e individuais das pessoas e das organizações. As bibliotecas, quer sejam especializadas ou gerais, podem contribuir significativamente neste contexto de mudanças, disseminando informação e colaborando com o sistema educacional do país. 
O bibliotecário, enquanto um dos agentes na divulgação e disseminação de informações tem papel primordial nesse contexto. Sua atuação tem como ponto forte interações pessoais intensas, o que exige que esteja capacitado para executar, com habilidade e competência, atividades e processos sob sua responsabilidade, com a qualidade desejada. Para tanto, há necessidade de se priorizar o trabalho em equipe, valorizar o aprendizado contínuo e o desenvolvimento de atitudes para que possam acompanhar as mudanças evolutivas das organizações e da sociedade.

O processo de formação continuada para a mediação do aprendizado está intimamente ligado à difusão de informações, capacitando a organização para criar, adquirir e transferir o conhecimento, modificando o comportamento para transformar o ambiente em um espaço de aprendizagem e construção de conhecimentos. As organizações que investem continuamente neste processo terão maior capacidade para reagir às mudanças e de se adaptarem mais rápido a elas.

Neste contexto, para Martucci (1998) o bibliotecário adquire conhecimentos oriundos de sua formação profissional, dos saberes das disciplinas e da sua experiência, maximizados pela prática profissional. A biblioteca pode ter sua função e espaço ampliados pelo dinamismo dos profissionais que nela atuam. Mizukami (1996 apud MARTUCCI, 1998, p. 65), ensina que:

\section{[...] essas concepções revelam uma compreensão atualizada da função social da biblioteca como espaço de informação, de cultura, de lazer e de convivência e demonstram a dimensão processual da apropriação e redimensionamento conceitual ao longo do processo de desenvolvimento profissional e o ethos onde atuam, as concepções, as práticas e os valores que o caracterizam.}

Diante das mudanças, os bibliotecários em seu ambiente de trabalho, no intuito de captar e transmitir o conhecimento, assumem um papel educativo. Esta ação é descrita por Martucci (1998, p. 89) quando aborda que "na interação com os usuários, muitas vezes, ocorrem situações de ensino-aprendizagem, nas quais o bibliotecário pode ser considerado um professor informal, o que o faz desenvolver um outro tipo de saber: o saber pedagógico". O papel de educador fica mais evidente na medida que o bibliotecário esteja capacitado na utilização das fontes e tenha habilidades e competências para expressar em linguagem, simplificada e compreensível, conceitos complexos que demandam linguagens especializadas. Além desses aspectos, deve estar 
preparado para indicar e utilizar fontes em seus vários formatos, suportes e funções, e adequadas aos problemas que se apresentam.

Silva (1993, p. 72) inclui a prática do bibliotecário "na categoria mais abrangente das práticas educativas que, devido a sua natureza específica, devem ser conscientizadoras, transformadoras e criadoras".

A designação de pessoas para trabalhar com a disseminação da informação junto aos diferentes públicos, deve levar em conta a formação geral e as habilidades dos indivíduos, que podem ser assim sumariadas: conhecimento interdisciplinar e especializado; habilidade de comunicação interpessoal oral e escrita; habilidades gerenciais (criatividade, flexibilidade, otimismo, trabalho em equipe); habilidades na exploração e tratamento de fontes de informação; comprometimento com a aprendizagem contínua e com o planejamento da carreira pessoal e, atualmente conhecimentos e habilidades para manusear e lidar inteligentemente com os sistemas automatizados. Para Dias e Belluzzo (2003) a adequada capacitação do profissional na utilização de modernas e eficazes ferramentas que agreguem valor à informação e novas abordagens de gerenciamento favorecerão a oferta de informações transmitindo o conhecimento contido nas fontes.

Para formar pessoas com o perfil acima indicado os administradores têm que adotar postura de liderança inovadora por meio da criação de programas de formação-emserviço. A formação-em-serviço constitui-se em um processo educativo contínuo com o objetivo de integrar pessoas ao ambiente de trabalho para garantir o seu bem estar e a qualidade dos serviços prestados.

Esta formação está ligada a algumas dimensões do conceito educação, tais como ensino, aprendizagem e mudança de comportamento. O ensino diz respeito à educação formalizada, desenvolvida em instituições e é programado em termos de tempo, objetivos, conteúdos, procedimentos e formas de avaliação. $\mathrm{O}$ ato ou a ação de assimilar o que foi ensinado, tornando-o cognoscível é a aprendizagem e seu efeito final é a modificação do modo de agir. A mudança de comportamento é considerada como resultado do processo educacional, mediante o qual as reações do aprendiz apresentam novas características, ressaltando sua inteligência e sua capacidade de realização. Pode- 
se afirmar que essas situações não podem ser consideradas isoladamente porque toda ação educativa compreende uma atuação sistêmica e livre (BELLUZZO, 1995).

O processo de aprendizado é contínuo, desenvolve-se ao longo da vida e ocorre quando novos conhecimentos são internalizados, provocando a modificação de pensamentos e de atitudes.

Levando em conta que as bibliotecas fazem parte do processo de aprendizado, pode-se afirmar que o trabalho do bibliotecário está diretamente relacionado à mediação do aprendizado, e que este profissional é peça importante em ambientes nos quais todos estejam em um processo contínuo de aprendizagem. Pois, o que é aprendido individualmente precisa estar acessível a outras pessoas da organização, aumentando o capital humano e consequentemente, o capital estrutural, o que resultará no capital intelectual da organização (CHIAVENATO, 2002).

Para que o bibliotecário atue na mediação do aprendizado é necessário que ele internalize quatro conceitos em suas atividades profissionais, descritos por Dudziak (2003), ou seja, intencionalidade, quando o bibliotecário direciona a interação e o aprendizado; reciprocidade, onde ambos aprendem; significado, quando a experiência é significativa para ambos e transcendência, quando a experiência é extrapolada para a vida do aprendiz. A ação educativa tem como objetivo melhorar ou desenvolver competências/habilidades necessárias à execução operacional dos processos/produtos ofertados, visando a modificação de atitudes produzindo um clima organizacional onde predomine o bem estar coletivo.

Para a formação em serviço de bibliotecários há necessidade de se definir algumas práticas de transmissão de informações com base em processos explícitos de aprendizagem que disponibilizem informações relevantes para a execução das atividades inerentes às funções a serem executadas no serviço.

Portanto, apresenta-se a seguir uma proposta metodológica para capacitação de equipes bibliotecárias visando a orientação e implementação de atividades que possam contribuir para que as bibliotecas se tornem espaços de aprendizado contínuo e permita 
que os bibliotecários possam internalizar conceitos que os possibilitem atuarem como mediadores do aprendizado no uso de fontes de informação.

\section{PROPOSTA METODOLÓGICA PARA CAPACITAÇÃO DE EQUIPES BIBLIOTECÁRIAS}

A comunicação interpessoal depende de competências específicas (profissionais e técnicas) exigindo o relacionamento direto e imediato do ser humano consigo mesmo, com o mundo e com os outros. Nesse processo de comunicação a compreensão e a interpretação são essenciais e intrínsecas à capacidade do receptor bem como do transmissor das informações necessárias para a absorção das idéias.

Para a criação de programas de capacitação de equipes bibliotecárias propõe-se a seguir uma metodologia dividida em quatro fases. A primeira fase diz respeito ao conhecimento do ambiente organizacional e suas necessidade para subsidiar as atividades de planejamento do procedimento formalizado e articulado para a formação em serviço. A segunda fase trata da elaboração de planos de ação onde são tomadas decisões quanto às estratégias de ação. A terceira fase corresponde à apresentação de um modelo para o desenvolvimento das ações programadas, ou seja, a implementação das ações. Finalmente, a quarta fase trata da avaliação de desempenho dos indivíduos após a implementação do programa de capacitação em serviço para os ajustes necessários.

\section{FASE 1 - PRELIMINARES (NÍVEL ESTRATÉGICO)}

Nesta fase, são definidas as políticas e diretrizes para nortear o planejamento, para favorecer a criação de oportunidades reais de aprendizado e não simplesmente programas de treinamento de pessoas. É também a fase na qual se estabelecem as metas, qualitativas e quantitativas, visando suprir necessidades presentes e futuras do pessoal na organização, levando-se em conta as atividades internas e os fatores do ambiente externo.

O programa de capacitação é planejado para aperfeiçoar recursos humanos contribuindo, entre outras vantagens, com o aumento da produtividade, melhor 
qualidade dos produtos e serviços oferecidos e deve ser pautado na identificação das necessidades de treinamento. $\mathrm{O}$ diagnóstico das necessidades de formação-em-serviço pode ser considerado também como uma fase que antecede o planejamento. $\mathrm{O}$ diagnóstico trata da análise da organização como um todo e do setor específico a ser trabalhado; dos processos/atividades (rotinas de trabalhos, fluxos dos serviços); das condições de melhorias dos recursos humanos (habilidades, conhecimentos e motivação das pessoas); e das condições ambientais e tecnológicas.

Antes de se elaborar um programa de capacitação é necessário definir claramente as razões ou os motivos que o justifiquem, por isso é importante realizar um levantamento das principais necessidades dos colaboradores, e esse trabalho precisa ser necessariamente realizado em conjunto, envolvendo as pessoas dos diferentes setores e a alta direção da biblioteca.

O levantamento de necessidades de capacitação é, antes de tudo, um trabalho de pesquisa que se inicia com a coleta de dados e se completa com a análise das informações obtidas. Quando esse trabalho é feito de forma eficiente, favorece o encontro de respostas às questões, tais como: quem necessita de capacitação?; onde há maior urgência de capacitação?; por que capacitar?; que tipo de capacitação é necessário?.

Buscar essas respostas constitui-se em uma tarefa exaustiva de investigar e estabelecer com acerto as reais necessidades de capacitação das pessoas nas organizações. Todavia, esse é o único meio capaz de proporcionar aos responsáveis pela capacitação, os recursos para oferecer o conteúdo adequado, o material condizente, as modalidades mais úteis. Somente dessa forma é possível oferecer à equipe o conhecimento necessário na medida certa, sem desperdício para a organização e, também, com o alcance da satisfação das pessoas.

A melhor maneira de se levantar as principais dificuldades dos colaboradores e suas causas é através da participação de todo o pessoal da biblioteca. É fundamental que as lideranças e os gestores da biblioteca tenham conhecimento e apoiem esse trabalho, pois sem a participação da alta direção qualquer iniciativa de capacitação estará fadada ao insucesso. Além disso, é importante a participação daqueles que realizam as tarefas. A 
participação das pessoas que realizam diferentes atividades propicia uma maior interação entre os mesmos e essa união evita que se elaborem programas que estejam longe de satisfazer as verdadeiras necessidades da equipe, isto porque haverá a participação daqueles que realmente realizam as tarefas diariamente.

Após esse levantamento, é feita uma análise dos dados, separando-se aqueles que correspondem às necessidades que serão atendidas prontamente daquelas cujo atendimento não requeira igual urgência. $\mathrm{Na}$ prática, este levantamento pode ser realizado por meio de entrevistas, questionários, da observação direta nos diferentes setores da biblioteca, em reuniões realizadas com todo o pessoal, ou com a utilização de instrumentos de melhoria contínua da qualidade, modelo proposto por Belluzzo (1995). Além desses métodos, durante a realização de modalidades básicas, é possível que o mediador desses processos educacionais, atento às indagações dos participantes, aos seus anseios, às suas dúvidas e dificuldades no exercício profissional, analise e extraia desse comportamento quais são as reais necessidades dos participantes. Esses procedimentos, conforme as circunstâncias e conveniências, podem ser usados isoladamente ou em combinação. O planejamento para a gestão de pessoas leva em conta as necessidades futuras quanto ao número e qualificação desejada das pessoas; o equilíbrio no que diz respeito às pessoas que atuam na organização e que, provavelmente, estarão no futuro; e a necessidade de dispensa ou capacitação para eliminar as lacunas de conhecimento e prover o colaborador de condições ideais ao desempenho desejável.

Além desses aspectos, o diagnóstico pressupõe a auditoria de Recursos Humanos (RH) que, segundo Chiavenatto (1999), consiste na análise sistemática das políticas e práticas de pessoal e a avaliação de seu funcionamento, tanto para a correção dos desvios como para sua melhoria contínua. O uso desta técnica é necessário para quantificar e qualificar as habilidades e o desempenho de cada colaborador, objetivando desta forma, identificar os clientes internos e as possibilidades de melhor aproveitamento. Um primeiro diagnóstico é a avaliação do nível de habilidade e competência da equipe quanto à compreensão, seleção, análise e uso das diferentes fontes de informação para a solução de problemas e o nível desta competência deve ser diagnosticado. 
O planejamento inclui a implantação de sistema de qualidade, sendo necessário:

- Identificar processos/atividades presentes na organização;

- Conscientizar, motivar e desenvolver habilidades das pessoas em relação à nova filosofia operacional;

- Controlar o desenvolvimento dos processos/atividades, medindo-se o trabalho executado para a verificação do grau de alcance das metas estabelecidas na etapa inicial do planejamento;

- Apontar ações corretivas para os processos/atividades resultantes da avaliação realizada.

A análise da problemática deve levar em conta as pessoas que estão ingressando na organização ou que acabaram de ser promovidas para um novo cargo. Outro aspecto relevante diz respeito às pessoas que já ocupam cargos ou funções há algum tempo e que, geralmente, oferecem resistência às mudanças, exigindo um trabalho específico de esclarecimento da necessidade de mudanças que virão com a capacitação em serviço.

Ao detectar as necessidades de capacitação das equipes bibliotecárias é importante fazer um paralelo das habilidades desse profissional com o perfil desejado. Para isso, é preciso ter claro quais as principais competências e habilidades que esse profissional deve ter.

Ao fazer um paralelo do comportamento desejado em relação ao comportamento real é possível detectar pontos não favoráveis, proporcionando um embasamento para a elaboração dos programas de capacitação.

Portanto, o levantamento de necessidades é um processo complexo, que exige busca de dados, análise e comparação com o perfil desejado. Além disso, é importante destacar o ambiente em que a biblioteca está inserida, e ter consciência que todo esse trabalho tem como objetivo principal oferecer um atendimento aos usuários com maior qualidade, criando um clima de satisfação também em relação aos clientes internos.

\section{FASE 2 - ELABORAÇÃo DE PLANOS DE AÇÃo (NÍVEL TÁTICO)}


Após o diagnóstico organizacional, passa-se ao planejamento dos programas de capacitação com a definição das modalidades, objetivos e a elaboração do planos de ação e de ensino, conforme o caso, com a identificação do público alvo, data/período, carga horária, ministradores, objetivos, conteúdo programático, procedimentos/técnicas de ensino, recursos, avaliação e bibliografia.

Para qualquer tipo de atividade ou serviço requer-se o planejamento prévio, o que envolve estabelecimento de objetivos e respectivas diretrizes, programas e procedimentos para atingir as metas propostas.

A escolha de um método de aprendizagem se fundamenta nos seguintes aspectos: na coerência entre o tipo de objetivo e o método de aprendizagem e nos custos de cada método.

Num programa de capacitação, o que importa são os resultados obtidos, e estes devem ser medidos em termos de aprendizagem do bibliotecário na condição de "educando" e no desempenho do bibliotecário enquanto colaborador.

O planejamento deve contar com a fixação dos objetivos, ou seja, o que se pretende alcançar com o programa proposto como, por exemplo, que modalidade seria melhor para o grupo; quais os assuntos que devem ser abordados; quais as necessidades que devem ser atendidas primeiramente; a quem deve ser ministrado o curso; e, finalmente, a escolha do conteúdo.

A seguir, deve-se estabelecer o controle do programa de capacitação, considerando:

- qual o melhor local para realização das ações selecionadas (se no próprio local de trabalho, ou fora dele; se durante ou após o expediente de trabalho);

- qual o tempo de duração do programa (quanto tempo se dispensará a cada fase do curso e tempo total);

- se o programa de capacitação tem relação com outros já desenvolvidos ou a serem desenvolvidos.

Um outro aspecto é a alocação de recursos financeiros tais como orçar quais os gastos primordiais como despesas com mediadores, materiais didáticos e de higiene, local do 
programa de capacitação, serviços de terceiros e, também, elaborar relatório orçamentário, para ter noção geral de quais os procedimentos a serem adotados, como por exemplo, se deve ser cobrada a taxa de inscrição.

Os procedimentos do programa devem contemplar o que segue:

- a apresentação do mediador e do grupo;

- a apresentação do conteúdo e ações do programa;

- os materiais ou meios que vão ser utilizados como: livros, filmes, cartazes, modelos, impressos, slides, diagramas, gravuras, entre outros;

- como ocorrerá a mediação dos processos;

- quem fará o acompanhamento dos participantes;

- as informações que deverão ser registradas em fichas (dossiês) do colaborador, para evidenciar a conclusão da atividade de capacitação;

- a quem caberá a aprovação final do plano.

Ao final deve-se organizar um cronograma de acompanhamento onde se tenha uma visão de todo o conjunto do programa, enfatizando as seguintes partes: a capacitação propriamente dita (título do projeto de capacitação; objetivo do projeto; local de realização das ações selecionadas; tempo de duração do projeto); os meios (quem será o mediador dos processos; a quem serão dirigidas as ações de capacitação; que auxílios para a capacitação deverão ser desenvolvidos e utilizados; como será efetuada a mediação; quem fará o acompanhamento dos participantes; que informações devem ser registradas; a quem caberá a aprovação final do plano); fins: apresentar por escrito, à administração, evidenciando fatos ou usando ilustrações, os resultados advindos da capacitação realizada; dar ênfase aos aspectos relativos à economia de tempo, dinheiro, esforço, espaço; fazer uma previsão do tempo destinado a cada parte do projeto de capacitação; indicar as oportunidades em que o mediador irá fazer uso dos diversos recursos físicos (auxílios acessórios): quadro-negro, slides, cartazes, entre outros; apresentar casos práticos e a maneira pela qual serão propostos aos participantes; o modo pelo qual o mediador deve obter, em determinados momentos, a participação dos colaboradores em capacitação; indicar as oportunidades em que fará a revisão ou recapitulação das ações empreendidas no desenvolvimento do programa. 


\section{FASE 3 - EXECUÇÃO DA PROPOSTA METODOLÓGICA}

Definidas as necessidades de capacitação, elaborados os respectivos programas, a ação imediata é a escolha dos métodos a serem utilizados para a sua execução. Não existe um método melhor do que o outro, mas o que é mais adequado a cada tipo de modalidade de capacitação. Vários fatores podem influir na escolha dos métodos, tais como nível de instrução dos colaboradores, objetivo e duração do programa, recursos humanos (mediadores) e didáticos disponíveis, etc. A coerência entre os objetivos e o método utilizado (inclusive o investimento necessário) deve ser considerada.

A eficácia do programa só será reconhecida se as metas estabelecidas pelo local de trabalho forem alcançadas e se os resultados obtidos satisfazerem, qualitativa e quantitativamente, às necessidades preestabelecidas.

Cabe destacar que os principais fatores que podem afetar a qualidade de execução do programa de capacitação estão relacionados à qualidade da equipe de colaboradores em capacitação; à seleção adequada dos participantes; à qualidade dos mediadores no que tange à facilidade de relacionamento, conhecimento e prática da especialidade abordada no programa; à qualidade do material e das técnicas empregadas; ao grau de envolvimento das lideranças; à adequação do programa. O programa de capacitação deve ser a solução para os problemas que deram origem ao estabelecimento dos objetivos ou uma forma de preparação das pessoas para o futuro.

O material de apoio, cuidadosamente planejado, facilita a execução do programa, a compreensão e o rendimento do participante, concretizando o processo de mediação para a inovação e desenvolvimento.

Aos mediadores cabem as qualificações necessárias na área de Serviço de Referência e Informação, sejam elas pedagógicas ou psicológicas, facilidade no relacionamento humano e, acima de tudo, motivação para a função. 
A avaliação das equipes envolvidas deve ser constante, durante todo o programa de capacitação. O mediador deve atentar sempre para as mudanças de comportamento, verificando e corrigindo no momento certo.

Assim, a equipe deve receber a atenção necessária para vencer as dificuldades dos primeiros momentos de capacitação e conservar sua motivação até o final. A fase final refere-se ao período de (re) capacitação, pois a ações desenvolvidas, devido à renovação das técnicas de trabalho e da tecnologia informacional, devem ser continuadas.

\section{FASE 4 - AVALIAÇÃO DO PROGRAMA DE CAPACITAÇÃO}

É a avaliação, portanto, que permite identificar as seguintes situações:

a) se o investimento nos programas de capacitação produziu realmente os resultados desejados;

b) se os objetivos foram alcançados;

c) se a equipe ficou satisfeita com o programa desenvolvido;

d) se as modalidades estão adequadas aos métodos reais de trabalho;

e) se os resultados do programa em relação ao desempenho da equipe estão de acordo com o programado;

f) se os critérios e padrões de capacitação estão de acordo com os objetivos do programa;

g) se os programas atingiram as necessidades da organização e a satisfação dos clientes internos e externos da biblioteca;

h) se haverá necessidade de modificações no processo de capacitação para aumentar sua qualidade;

i) se a relação custo/efetividade foi vantajosa.

A avaliação de desempenho consiste em uma apreciação sistemática da eficácia do trabalho de uma pessoa, em relação aos objetivos propostos pela organização. Por isso é de fundamental importância, que os objetivos da organização estejam sempre bem definidos e explicitados, pois quando estes objetivos não são claros, pode ocorrer desvios nos resultados. Além de apreciar a eficácia do trabalho, a avaliação de desempenho deverá também medir os potenciais de desenvolvimento das pessoas, que devem ser identificados, desenvolvidos e aproveitados. 
Os processos de avaliação de desempenho humano de uma organização podem ser informais e formais. A avaliação informal, ocorre no cotidiano da organização e consiste no processo contínuo de oferecer aos colaboradores, informações sobre como estão realizando o trabalho, em um clima de naturalidade e informalidade. Geralmente, os resultados estão voltados à correção de desempenhos inadequados.

Por outro lado, a avaliação formal consiste na aplicação de métodos pré-estabelecidos, sistematicamente, de acordo com os objetivos da organização, como também identificar as necessidades de capacitação adicional.

A avaliação da capacitação pode ser dividida em quatro etapas:

$1^{a}$ ) avaliação de reações: são avaliadas as opiniões e atitudes dos participantes a respeito do programa ao qual foram submetidos (métodos utilizados, atuação do mediador, horário, instalações). Nesta fase não se considera a aquisição de conhecimentos, mas, somente, o grau em que os participantes aceitaram o programa.

$2^{\mathrm{a}}$ ) avaliação de aprendizagem: verifica-se até que ponto os conhecimentos foram assimilados pelos participantes, isto é, se eles realmente apreenderam as teorias, as técnicas e os métodos de trabalho ensinados. Requer a utilização de diferentes técnicas tais como: testes objetivos (conhecimento), observação do desempenho (habilidades) auto relatório e observação direta de comportamento durante a instrução (atitudes).

$3^{a}$ ) avaliação do comportamento: ocorre durante o desempenho profissional do bibliotecário e após a sua capacitação; pode-se utilizar a observação e o questionário. Para haver mudança de comportamento, o participante precisa reconhecer suas limitações e querer efetivamente mudar; precisa de apoio e orientação para a mudança. $4^{\mathrm{a}}$ ) avaliação dos resultados: é feita uma avaliação global dos resultados obtidos nas outras fases, a fim de se verificar o grau de validade do programa de capacitação, as falhas e deficiências que devem ser corrigidas nos programas futuros e as providências que se devem tomar durante o período de acompanhamento do participante após a sua volta ao ambiente de trabalho.

Para a avaliação de resultados de capacitação podem ser usados formulários, entrevistas, questionários, provas escritas, observação direta ou quaisquer outros instrumentos que forem julgados adequados a casos específicos. 
Considerando o aspecto pedagógico das atividades de capacitação, quase tudo o que aprendemos requer uma ação de nossa parte, o que, por sua vez, traz conseqüências. À medida que alguém aprende e comporta-se de uma determinada maneira, o conhecimento dos efeitos de tal comportamento é importante, bem como sua correção e reforço do processo de aprendizado.

O conhecimento dos resultados é um fator de retroalimentação que fornece informações, por meio das quais os erros são corrigidos e o desempenho conseqüentemente é lapidado. A avaliação no aspecto pedagógico do programa de capacitação deve focalizar a qualidade e preparo dos mediadores, do material de apoio e a qualidade dos participantes.

\section{CONSIDERAÇÕES FINAIS}

Dada a carência de reflexões sobre a temática na literatura brasileira que favoreça mudanças dos paradigmas vigentes na área de Biblioteconomia e Ciência da Informação, o trabalho buscou demonstrar que mudanças de comportamento, com base em metodologias científicas com comprovada eficácia, no ambiente interno ou externo, certamente contribuirão para o desenvolvimento de trabalho cooperativo e ações que favoreçam a qualidade e a produtividade dos serviços bibliotecários, o que pressupõe avaliação sistemática e a oferta de programas de capacitação voltados para o atendimento de usuários, de forma eficiente e eficaz, com a qualidade desejada, tanto em ambientes tradicionais como no mundo da informação eletrônica.

A verificação da aplicabilidade da metodologia e sua adequação aos objetivos propostos dependerá da disponibilidade de recursos e da organização na qual será utilizada, podendo abarcar desde as modalidades mais tradicionais àquelas consideradas mais avançadas, requerendo até mesmo plataformas de e-learning.

\section{REFERÊNCIAS}

BELLUZZO, R. C. B. Da capacitação de recursos humanos à gestão da qualidade em bibliotecas universitárias: paradigmas teórico-prático para ambiente de serviço de referência e informação. 1995. 259 f. Tese (Doutorado em Ciências da Comunicação) Escola de Comunicações e Artes, Universidade de São Paulo, São Paulo, 1995. 
CHIAVENATO, I. Treinamento e desenvolvimento de recursos humanos: como incrementar talentos na empresa. São Paulo: Atlas, 1999. 161 p.

CHIAVENATO, I. Gerenciando pessoas: como transformar gerentes em gestores de pessoas. 4. ed. São Paulo: Prentice Hall, 2002. 271 p.

DIAS, M. M. K.; BELLUZZO, R. C. B. Gestão da informação em ciência e tecnologia sob a ótica do cliente. Bauru: EDUSC, 2003. 184 p.

DUDZIAK, E. A. Information Literacy: princípios, filosofia e prática. Ciência da Informação, Brasília, v. 32, n. 1, jan./abr. 2003.

MARTUCCI, E. M. O conhecimento prático do bibliotecário de referência. 1998. 187 f. Tese (Doutorado em Educação) - Centro de Educação e Ciências Humanas, Universidade Federal de São Carlos, São Carlos, 1998.

SILVA, E. L. da.; CUNHA, M. V. da. A formação profissional no século XXI: desafios e dilemas. Ciência da Informação, Brasília, v. 31, n. 3, p. 77-82, set./dez. 2002.

SILVA, E. T. A dimensão pedagógica do trabalho do bibliotecário. In:

Leitura na escola e na biblioteca. 4. ed. Campinas: Papirus, 1993.

\section{MARIA MATILDE KRONKA DIAS}

Doutora em Ciências da Comunicação pela Universidade de São Paulo e Professora Adjunta do Departamento de Ciência da Informação da Universidade Federal de São Carlos.

e-mail:mmkd@terra.com.br

\section{REGINA CELIA BAPTISTA BELLUZZO}

Professora Pesquisadora junto à Pró-reitoria de Pesquisa e Pós-graduação da Universidade Sagrado Coração, onde também é Pró-reitora Acadêmica. Doutora em Ciências da Comunicação pela Universidade de São Paulo e Pós-doutorado em Educação Escolar pela UNESP-Araraquara e-mail: rbelluzzo@travelnet.com.br

\section{FÁBIO ASSIS PINHO}

Mestrando no Programa de Pós-Graduação em Ciência da Informação, Faculdade de Filosofia e Ciência, UNESP-Marília, SP

e-mail: fabio@fcav.unesp.br

\section{DANIELA PIRES}

Estudante de graduação de Biblioteconomia e Ciência da Informação, Universidade Federal de São Carlos

e-mail: danicasbr@yahoo.com.br

Artigo aceito para publicação em: 01/05/2004. 